\title{
South Africa failing women as abuse of maternity patients runs rampant, report says
}

A lack of oversight and accountability for widespread abuse of maternity patients by health care workers in South Africa is putting women and their newborns at increasing risk of injury and death, an international human rights group asserts.

Instances of health workers physically and verbally abusing maternity patients are so rife in the country's public health system that pregnant women are intentionally delaying or forgoing hospital care, even at great risk to their babies and their lives, according to a Human Rights Watch report, Stop Making Excuses: Accountability for Maternal Health Care in South Africa (www.hrw.org/sites/default/files/reports /sawrd0811webwcover.pdf).

"The world tends to treat maternal mortality as a resource issue, yet in South Africa it's not a lack of resources but how they're being used that's the problem," says Agnes Odhiambo, a women's rights researcher at Human Rights Watch and author of the report. "Pumping more money or more health workers into the system without demanding accountability for the quality of care women receive is ultimately a waste and is not saving lives."

South Africa's maternal mortality ratio has more than quadrupled over the past decade, from 150 deaths per 100000 live births in 1998 to 625 in 2007 , despite continuing improvements in coverage for antenatal care and access to skilled attendants at delivery, the report states. A growing percentage of these deaths - more than a third by government estimates - are attributable to "avoidable factors, missed opportunities and substandard care" in the health system. However, these increases may be the result of improved reporting mechanisms (www.doh.gov.za/docs/reports /2007/savingmothers.pdf).

The 66-page report is based on field research conducted between August

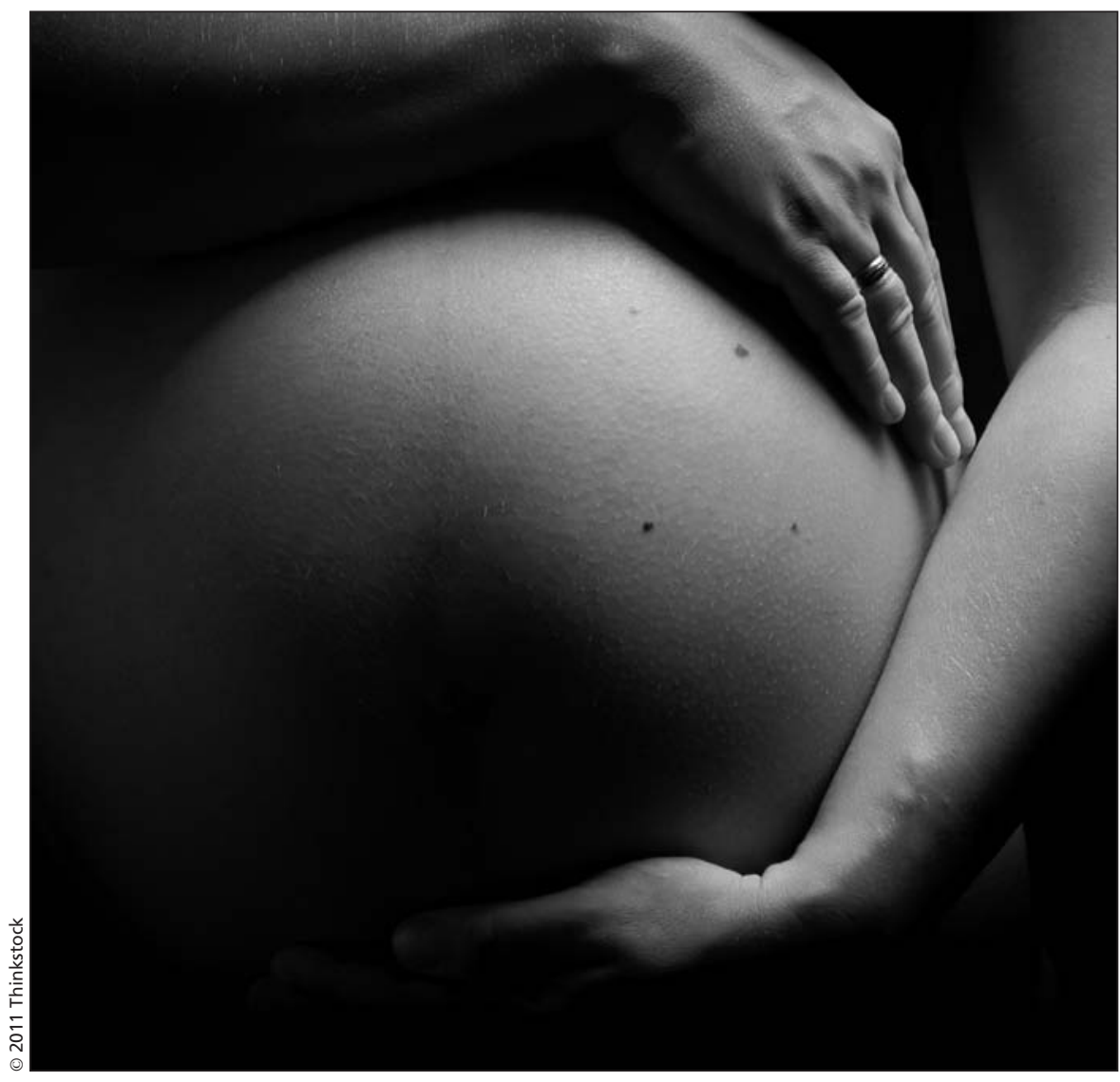

Instances of health workers physically and verbally abusing maternity patients are so rife in South Africa that pregnant women are intentionally delaying or forgoing hospital care, according to Human Rights Watch.

2010 and April 2011, including interviews with women who experienced a litany of abuses at the hands of health workers, such as pinching, slapping and rough handling during labour.

Women also described rampant verbal abuse, including being ridiculed when pleading for assistance or pain relief, and being berated for "messing up" when they bled on the floor during labour. Many are later forced to clean up their own blood, the report states.

"It's become so normal some nurses don't understand why it's a problem to slap or shout at women in labour," says Odhiambo. "Some say it's necessary to get patients to follow directions, and it's for their own good."
Such abuse was often accompanied by substandard care, she adds. The report documents treatment delays, nurses who ignored calls for help and facilities that discharged women inappropriately without pain medication or antibiotics and refused admission to women in labour, sometimes without examining them.

High-level health officials are aware of the problem and have implemented patient complaint systems, but incompetence and a lack of accountability in management at the district and facility level have stymied progress, Odhiambo explains.

"The health minister has signed a contract with the president in which 
maternal mortality is one of his key performance areas, yet nothing has been signed by managers at the provincial, district or facility levels," she says. "Instead, you have people without backgrounds in health care running hospitals, without vision or ownership for those institutions, and they shift the blame when patients report abuse."

Some health workers resent the complaints system, seeing it as punitive, and discourage or interfere with patients' rights to lodge complaints, the report states. Even when a complaint is lodged, health facilities often shield abusive staff and fail to respond or provide redress.

"We have the mechanisms to report and handle abuses, but the complaints are just being gathered and are not being used to fashion solutions," Odhiambo says.

Another part of the problem is that many frontline workers, particularly nurses, receive largely theoretical educations and are ill-prepared for the requirements of their jobs, Odhiambo explains. "For nurses trained in the universities, they go to the hospital and are shocked by what they find there, and are not prepared to deal with it."
Trade unions and professional organizations have also contributed to the mess by protecting their members at any cost, she adds. "They're not preaching to their members that they need to be accountable for the care they provide, and when their members become involved in misconduct, they protect rather than discipline them."

The government is now reassessing the competencies of facility managers, with the aim of retraining or removing the underqualified and incompetent. Lauren Vogel, CMAJ

CMAJ 2011. DOI:10.1503/cmaj.109-3962 